\title{
Hemodynamic and Metabolic Effects of
}

\section{Hypertonic Saline Infusion in Normovolemic Dogs}

\author{
Susumu Ishikawa, ${ }^{1}$ Shigeru Oki, ${ }^{1}$ Kiyohiro Oshima, ${ }^{1}$ \\ Masato Muraoka, ${ }^{1}$ Jun Murakami, ${ }^{1} \quad$ Taro Nameki, ${ }^{1}$ \\ Masayuki Sugano, ${ }^{1}$ Yutaka Hasegawa, ${ }^{1}$ Toru Takahashi, ${ }^{1}$ \\ and Yasuo Morishita ${ }^{1}$
}

\begin{abstract}
Aims : The hemodynamic and metabolic effects of hypertonic saline (HTS) infusion were studied in normovolemic dogs. Methods : Seven adult mongrel dogs, weighing 10 to $15 \mathrm{~kg}$, were used in this study. Under general anesthesia, the pericardium was opened via a right thoracotomy. High-dosage of HTS $(10 \% \mathrm{NaCl}, 5 \mathrm{ml} / \mathrm{kg})$ was infused intravenously within a five minute period. Results : Systemic blood pressure significantly increased from $110 \pm 10 \mathrm{mmHg}$ to $125 \pm 10 \mathrm{mmHg}$. Central venous pressure and left atrial pressure also significantly increased $(4.6 \pm 1.7 \rightarrow 9.3 \pm 1.9 \mathrm{mmHg}, 3.5 \pm 1.4 \rightarrow 5.7 \pm 2.4 \mathrm{mmHg}$, respectively). Cardiac output increased significantly from $2.0 \pm 0.2 \mathrm{~L} / \mathrm{min}$ to $3.0 \pm 0.2 \mathrm{~L} / \mathrm{min} 10$ minutes after HTS infusion. Arterial blood gas analysis revealed that $\mathrm{pH}$, base excess and $\mathrm{HCO}^{-}$had decreased significantly 10 minutes after HTS infusion. Hemoglobin and hematocrit levels significantly decreased after HTS infusion. Although $\mathrm{O}_{2}$ content decreased significantly, the myocardial $\mathrm{O}_{2}$ extraction rate did not change. Serum sodium and chloride values increased significantly and sustained those levels until 60 minutes after HTS infusion. Conclusions : In conclusion, HTS infusion remains a simple and valuable clinical procedure to use in restoring adequate hemodynamic conditions after hypovolemic shock. (Kitakanto Med J $2004 ; 54: 109 \sim 112$ )
\end{abstract}

Key words : hypertonic saline, electrolyte, hemodynamic effect, metabolic effect

\section{Introduction}

The infusion of small volumes of hypertonic saline (HTS) solution has been widely accepted as an effective procedure in restoring adequate hemodynamic conditions after hypovolemic shock. ${ }^{1}$ Other effects of HTS have been recently reported including the enhance of host response to inflammatory conditions. ${ }^{2}$ The aim of this study was to examine the hemodynamic and metabolic effects of HTS infusion in normovolemic dogs.

\section{Materials and Methods}

A total number of seven adult mongrel dogs, weighing 10 to $15 \mathrm{~kg}$, were used in this study. After intramuscular injection of ketamine hydrochloride
$(5 \mathrm{mg} / \mathrm{kg})$, the dogs were anesthetized with pentobarbiturate $(20 \mathrm{mg} / \mathrm{kg})$ and pancuronium bromide $(2 \mathrm{mg})$, intubated, and connected to a Harvard respirator (Bodine Electric Co., Chicago, Ill). Through a right thoracotomy via the $4^{\text {th }}$ or $5^{\text {th }}$ intercostals space, the pericardium was opened parallel to the phrenic nerve. Catheters were inserted into the superior vena cava and the left atrium via the right and left atrial appendage, respectively, in order to measure atrial pressure. A flow meter probe was put on the ascending aorta to measure cardiac output. A high-dosage of HTS (10\% $\mathrm{NaCl}, 5 \mathrm{ml} / \mathrm{kg}$ ) was infused intravenously within a five minute period. Hemodynamics, systemic artery and coronary sinus blood gas, and serum electrolytes were measured both prior to and after HTS infusion.

All animals in this study received humane care in

1 Department of Thoracic and Visceral Organ Surgery (Second Department of Surgery), Gunma University Graduate School of Medicine, Maebashi, Japan

Received: February 3, 2003

Address: SUSUMU ISHIKAWA Department of Thoracic and Visceral Organ Surgery (Second Department of Surgery), Gunma University Graduate School of Medicine, Maebashi, Gunma 371-8511, Japan 
Table 1 Hemodynamic Condition

\begin{tabular}{lcccc}
\hline & \multicolumn{2}{c}{ Hypertonic Saline Infusion } & & \\
& Prior to & After & \%Change & p \\
\hline Hemodynamics & & & & \\
Systolic BP (mmHg) & $110 \pm 10$ & $125 \pm 10$ & 114 & 0.0462 \\
Diastolic BP (mmHg) & $65 \pm 8$ & $63 \pm 9$ & 97 & 0.7143 \\
Systolic-Diastolic BP & $50 \pm 4$ & $62 \pm 5$ & 124 & 0.1207 \\
Pulse rates (/min.) & $176 \pm 8$ & $164 \pm 6$ & 93 & 0.1190 \\
CVP (mmHg) & $4.6 \pm 1.7$ & $9.3 \pm 1.9$ & 200 & 0.0073 \\
Left atrial pressure (mmHg) & $3.5 \pm 1.4$ & $5.7 \pm 2.4$ & 163 & 0.0097 \\
Cardiac output (L/min.) & $2.0 \pm 0.2$ & $3.0 \pm 0.2$ & 150 & 0.040 \\
SVR (dynes $\cdot \sec \cdot \mathrm{cm}^{5}$ ) & $3140 \pm 543$ & $2006 \pm 312$ & 64 & 0.037 \\
\hline
\end{tabular}

- Hemodynamics were measured prior to and 10 minutes after hypertonic saline infusion.

- BP : blood pressure, CVP : central venous pressure

- SVR : systemic vascular resistance

Table 2 Blood Gas Analysis

\begin{tabular}{lcccc}
\hline & \multicolumn{2}{c}{ Hypertonic Saline Infusion } & & \\
& Prior to & After & \%Change & $\mathrm{p}$ \\
\hline Arterial blood gas analysis & & & & \\
PH & $7.35 \pm 0.02$ & $7.29 \pm 0.02$ & 99 & 0.0006 \\
PCO2 & $35 \pm 3$ & $35 \pm 3$ & 100 & 0.2185 \\
PO2 & $109 \pm 23$ & $110 \pm 20$ & 101 & 0.8061 \\
Base excess & $-5.4 \pm 1.0$ & $-8.0 \pm 0.9$ & 148 & 0.003 \\
HCO3- & $18.9 \pm 1.2$ & $16.9 \pm 0.9$ & 89 & 0.0096 \\
Osm & $286 \pm 3$ & $330 \pm 4$ & 115 & $<0.0001$ \\
Hb & $8.9 \pm 0.7$ & $7.0 \pm 0.7$ & 79 & 0.0013 \\
Ht & $27 \pm 2$ & $21 \pm 2$ & 78 & 0.0017 \\
$\mathrm{O}_{2}$ content (mg/d) & & & 83 & $<0.0001$ \\
Artery & $11.7 \pm 1.1$ & $9.7 \pm 1.0$ & 0.0656 \\
Coronary sinus & $7.4 \pm 0.9$ & $5.9 \pm 0.7$ & 110 & 0.6223 \\
MO2ER (\%) & $31 \pm 7$ & $34 \pm 2$ & & \\
\hline
\end{tabular}

- Blood gas was analyzed prior to and at 10minutes after hypertonic saline infusion.

- $\mathrm{MO}_{2} \mathrm{ER}$ : myocardial oxygen extraction rate

Table 3 Changes of Serum Electrolytes

\begin{tabular}{lccccc}
\hline & \multicolumn{3}{c}{ After Hypertonic Saline Infusion } \\
& Prior to & 10min. & 20min. & 30min. & $60 \mathrm{~min}$. \\
\hline Electrolytes $(\mathrm{mEq} / \mathrm{L})$ & & & & \\
$\quad$ Sodium $\left(\mathrm{Na}^{+}\right)$ & $144 \pm 1$ & $168 \pm 2^{* *}$ & $159 \pm 4^{* *}$ & $161 \pm 5^{*}$ & $161 \pm 5^{*}$ \\
Potassium $\left(\mathrm{K}^{+}\right)$ & $3.6 \pm 0.2$ & $2.9 \pm 0.1^{* *}$ & $3.5 \pm 0.2$ & $3.8 \pm 0.5$ & $3.8 \pm 0.2$ \\
Chloride $\left(\mathrm{Cl}^{-}\right)$ & $113 \pm 2$ & $141 \pm 3^{* *}$ & $133 \pm 6^{* *}$ & $136 \pm 9^{*}$ & $135 \pm 9^{*}$ \\
Calcium $\left(\mathrm{Ca}^{2+}\right)$ & $1.1 \pm 0.04$ & $1.0 \pm 0.02$ & $1.1 \pm 0.1$ & $1.0 \pm 0.1$ & $1.0 \pm 0.1$ \\
\hline & & & $* *: \mathrm{p}<0.01, *: \mathrm{p}<0.05$
\end{tabular}

compliance with the "Guide for the Care and Use of Laboratory Animals," prepared by the Institute of Laboratory Animal Resources and Published by the National Institute of Health (NIH Publication No. 86-23, revised 1985).

Statistical analysis was conducted using SAS version 5.0 software (SAS Institute, Inc, Cary, NC). The values were expressed as the mean \pm the standard error of the mean (SEM). The Students' T-test and the $\chi^{2}$-test were used for statistical analysis, and a $p$ value of less than 0.05 was considered to be significant.

\section{Results}

Hemodynamics and blood gas were measured 10 minutes after HTS infusion and compared to those values prior to infusion. Systemic blood pressure was significantly elevated from $110 \pm 10 \mathrm{mmHg}$ to $125 \pm$ $10 \mathrm{mmHg}$. Central venous pressure and left atrial pressure increased significantly $(4.6 \pm 1.7 \rightarrow 9.3 \pm$ $1.9 \mathrm{mmHg}, \quad 3.5 \pm 1.4 \rightarrow 5.7 \pm 2.4 \mathrm{mmHg}, \quad$ respectively). Cardiac output increased significantly from $2.0 \pm 0.2 \mathrm{~L} /$ min to $3.0 \pm 0.2 \mathrm{~L} / \mathrm{min} 10$ minutes after HTS infusion (Table 1).

Arterial blood gas analysis revealed that the $\mathrm{pH}$, base excess and $\mathrm{HCO}^{-}$had decreased significantly 10 minutes after HTS infusion. Hemoglobin and hematocrit levels significantly decreased after HTS infusion. The extracellular fluid (ECF) volume was 
calculated by hemoglobin levels had expanded by $27 \%$ after HTS infusion. $\mathrm{O}_{2}$ content had decreased significantly, however the myocardial $\mathrm{O}_{2}$ extraction rate did not change (Table 2).

Serum sodium and chloride levels increased significantly after HTS infusion $(144 \pm 1 \rightarrow 168 \pm 2 \mathrm{mEq} / \mathrm{L}$, $113 \pm 2 \rightarrow 141 \pm 3 \mathrm{mEq} / \mathrm{L}$, respectively). These significant increases continued even 60 minutes after HTS infusion. Serum potassium levels decreased significantly from $3.6 \pm 0.2 \mathrm{mEq} / \mathrm{L}$ to $2.9 \pm 0.1 \mathrm{mEq} / \mathrm{L}$ after HTS infusion, but recovered 20 minutes after HTS infusion. Serum calcium levels did not change after HTS infusion (Table 3).

\section{Discussion}

HTS has been used clinically as an intravenous resuscitation fluid in patients with hypovolemic conditions. Prehospital infusion has been recommended recently to improve patients' survival. ${ }^{3}$ In this study, systolic blood pressure, central venous pressure and left atrial pressure was significantly elevated, and cardiac output increased by $50 \%$ associated with a decrease of systemic vascular resistance. These results were similar to those of previous reports. ${ }^{4}$ These hemodynamic changes were probably caused by volume expansion. When considering an increase of cardiac output, large volume expansion effects can be obtained by solitary HTS infusion. Vassar and his colleagues reported that the addition of a colloid, in the form of $6 \%$ dextran 70, did not offer any additional benefit at least in the setting of rapid urban transport. ${ }^{5}$ Thus, solitary HTS infusion is considered to be adequate to generate the sufficient volume expansion. The mechanisms governing the duration of the extracellular fluid volume (ECF) expansion as a result of intravenous infusion of HTS solution are poorly understood. The sodium excretion has been reported to be inversely proportional to the duration of the extracellular volume expansion by $7.5 \%$ saline. $^{6}$

The volume expansion by HTS infusion is caused by hemodilution The hemodilution at the conclusion of infusions averaged $7.7 \%$ in trauma patients and $9.1 \%$ in the control group, but the dilution was better maintained after trauma. ${ }^{7}$ In our study, hemoglobin levels changed from 8.9 to 7.0 , thus extracellular fluid (ECF) volume had expanded by $27 \%$ after HTS infusion. In an experimental study with normovolemic horses by Moon et al., ${ }^{4}$ a $23 \%$ expansion of volume was obtained, which was similar to our results. They reported that arterial and venous blood oxygen content decreased significantly probably due to hemodilution. ${ }^{4}$ In our study, arterial blood oxygen content decreased significantly, however, there was no significant change in the myocardial oxygen extraction rate. Thus, adverse effects of hemodilution did not seem to be significant relative to cardiac metabolism. In our study, serum sodium and chloride levels were significantly elevated probably due to the rapid five minute infusion of HTS. According to a report by Bhatt and his colleagues, ${ }^{8}$ there was no significant rise in serum sodium levels; peak levels were reached within 4 hours and then declined. The optimal concentration, infusion rate and dosage of a saline solution for resuscitation are still controversial. Cai and his colleagues reported that using $7.5 \%$ sodium chloride solution equivalent to $15 \%$ of the lost blood at an infusion rate of $20 \mathrm{ml} / \mathrm{min}$ achieved the best resuscitation result. ${ }^{9}$

In addition to hemodynamic effects, new effects of HTS have been recently recognized. Shields and his colleagues $^{2}$ reported that HTS enhanced the host response to bacterial challenge by augmenting receptor-independent neutrophil intracellular superoxide formation. Hypertonic saline resuscitation also limited neutrophil activation after traumahemorrhagic shock. ${ }^{11}$ HTS has been reported to be effective in management following cardiac surgery with a decrease of perioperative weight gain due to an intense diuretic effect, which reduced intraoperative fluid retention. ${ }^{11}$ In conclusion, solitary HTS infusion remains a simple and valuable clinical procedure not only from the aspect of volume expansion but also including other effects such as anti-inflammatory and diuretic reactions.

\section{Refereces}

1. Younes RN, Aun F, Accioly CQ, et al. Hypertonic solutions in the treatment of hypovolemic shock: a prospective, randomized study in patients admitted to the emergency room. Surgery. $1992 ; 111: 380-385$.

2. Shields CJ, O'Sullivan AW, Wang JH, et al. Hypertonic saline enhances host response to bacterial challenge by augmenting receptorindependent neutrophil intracellular superoxide formation. Ann Surg. 2003; 238: 249-257.

3. Vassar MJ, Fischer RP, O'Brien PE, et al. A multicenter trial for resuscitation of injured patients with $7.5 \%$ sodium chloride. The effect of added dextran 70. The Multicenter Group for the Study of Hypertonic Saline in Trauma Patients. Arch Surg. 1993; 128: 1003-1011.

4. Moon PF, Snyder JR, Haskins SC, et al. Effects of a highly concentrated hypertonic saline-dextran volume expander on cardiopulmonary function in anesthetized normovolemic horses. Am J Vet Res. 1991; 52 : 1611-1618.

5. Vassar MJ, Perry CA, Holcroft JW. Prehospital resuscitation of hypotensive trauma patients with 
7.5\% $\mathrm{NaCl}$ versus $7.5 \% \mathrm{NaCl}$ with added dextran : a controlled trial. J Trauma. 1993; 34 : 622-632.

6. Svensen $\mathrm{CH}$, Waldrop $\mathrm{KS}$, Edsberg L, et al. Natriuresis and the extracellular volume expansion by hypertonic saline. J Surg Res. 2003; 113 : 6-12.

7. Svensen C, Sjostrand F, Hahn RG. Volume kinetics of intravenous fluid therapy in the prehospital setting. Prehospital Disaster Med. 2001; 16: 9-13.

8. Bhatt RV, Patel NF, Pathak ND, Doraswamy S. Electrolyte studies in blood, urine and liquor after intra-amniotic instillation of $20 \%$ sodium chlo- ride. J Obstet Gynaecol India. 1977; 27 : 5052.

9. Cai X, Huang D, Mu Y, et al. Hypertonic saline solution resuscitation in hemorrhagic shock dogs. Chin J Traumatol. 2002; 5 : 180-185.

10. Deitch EA, Shi HP, Feketeova E, et al. Hypertonic saline resuscitation limits neutrophil activation after trauma-hemorrhagic shock. Shock. 2003 ; 19 : 328-33.

11. Jarvela $\mathrm{K}$, Kaukinen $\mathrm{S}$. Hypertonic saline (7.5\%) decreases perioperative weight gain following cardiac surgery. J Cardiothorac Vasc Anesth. 2002 ; $16: 43-46$. 